\title{
BUENOS AIRES Y LA GUERRA DEL PACÍFICO. ACTORES SUBALTERNOS EN LA OCUPACIÓN DE LIMA
}

\author{
BUENOS AIRES AND THE PACIFIC WAR. \\ SUBALTERN ACTORS IN THE OCCUPATION OF LIMA
}

\author{
Gerardo Trillo Auqui*
}

\begin{abstract}
La guerra del Pacífico fue un acontecimiento que marcó el desarrollo de la historia de América Latina, con mucho más ahínco en los países directamente involucrados, unos más y otros menos; sin embargo el discurso historiográfico ha delineado los caminos de la reflexión, haciendo creer que nacionalismo y patriotismo son los únicos discursos que han imperado en la comprensión de tan infausta guerra; dejando de lado y casi ocultando la trascendencia que el conflicto tuvo en diversos grupos subalternos de América Latina; aquellos grupos de individuos que no estando directamente implicados en la contienda en el alza de las armas o el enfrentamiento frente a frente, también se vieron inmiscuidos en el acontecer diario de los hechos que ocurrían en el campo de batalla. Así, estudiamos un caso particular: la manifestación pública que hicieran las comunidades de extranjeros en la ciudad de Buenos Aires, a partir de las noticias que recibían de la ocupación de la capital peruana por parte de las tropas chilenas en enero de 1881; haciendo hincapié en su respuesta hacia las noticias respecto de la matanza de extranjeros, organizando un Indignation Meeting que captó toda la atención de la prensa bonaerense por esos meses.
\end{abstract}

Palabras claves: Guerra del Pacífico, ocupación de Lima, comunidad de extranjeros.

The War of Pacific was an event that has been marked in the development of the history of Latin America, with more zeal in the countries involved, some more than others; however the historiographical discourse has outlined the ways of thinking, making believe that nationalism and patriotism are the only discourses that have prevailed in understanding as infamous war; aside and almost hiding the significance that the conflict had on various subaltern groups in Latin America; those groups of individuals not being directly involved in the conflict in the rise of arms or face to face confrontation, were also embroiled in the daily happenings of the events taking place in the battlefield. So, we study a particular case: the public protest made for the communities of foreigners in the city of Buenos Aires, after receiving news of the occupation of the Peruvian capital by Chilean troops in January 1881; emphasizing its response to the news about the killing of foreigners, organizing a Indignation Meeting that caught the attention of the Buenos Aires newspaper for those months.

Key words: War of the Pacific, occupation of Lima, foreign community.

\section{Introducción}

La guerra del Pacífico ha significado un hecho histórico de trascendencia regional y que ha dejado su marca en las generaciones que siguieron a aquellas que les tocó vivir los acontecimientos en el mismo momento de sucedidos. Lo relativo a la historiografía abarrota bibliotecas y las fuentes al respecto aún se pueden encontrar en repositorios como novedad, inéditas o incluso olvidadas; sin embargo, el desarrollo de la historia como disciplina académica ha permitido que dichas fuentes no se agoten y que, por el contrario, permitan complementar cada vez más el conocimiento que tenemos concerniente a los sucesos de tan infausta guerra. En ese sentido, enfoques desde la historia militar, económica, social y política han dado luz a excelentes estudios e investigaciones desde los tres países comprometidos, así también la historia de las relaciones internacionales nos ha mostrado que el impacto de la guerra trascendió las fronteras de los directamente implicados, estudios iniciales como los de Pedro Irigoyen (1919 y 1921) son muestras tempranas del interés en buscar más explicaciones a los hechos. No podemos dejar de mencionar estudios que señalan la presencia de la guerra en otros países, como son aquellos que, considerando la fuente hemerográfica, ha mostrado Norman Guice en un artículo titulado "Giving Peru a voice: Federico Larrañaga and El Canal de Panamá", el que busca historiar el trabajo del Cónsul General del Perú en Panamá Larrañaga, quien fundó una publicación en español, inglés y francés como portavoz del régimen de Piérola en Centroamérica y que tenía

* Universidad Nacional Mayor de San Marcos, Biblioteca Nacional del Perú. Correo electrónico: gerardotrillo@gmail.com 
como uno de sus más importantes colaboradores a Ricardo Palma, quien enviaba sus artículos acerca de la guerra con el seudónimo de Hiram ${ }^{1}$. Asimismo, Cecilia Wu Brading ha mostrado el mismo interés de brindar fuentes del impacto de la guerra en otras regiones, así, Diplomacia mexicana en América del Sur y la Guerra del Pacífico 1878-1879(1995) es otra muestra de la necesidad de historiar lo que por ser implicadas otras realidades terminaban en el contexto de dicha guerra. Pero la bibliografía relacionada a otro espacio que no estuvo directamente involucrada es la que se refiere a la participación de Argentina en dicho proceso, así, sin dejar de mencionar a Pedro Irigoyen, estudios recientes han tratado de dar respuesta a una de las interrogantes más cruciales sobre la participación de la República de La Plata, esta es sobre su neutralidad; Alicia Vidaurreta (1988) señala que la neutralidad argentina en la contienda resulta ficticia y contradictoria, cuando al mismo tiempo, los grupos de presión económica se mantuvieron en estrecho contacto con Bolivia y Perú, países a los que se vendió armamento y mercadería. Los intereses de esa vasta red comercial se mantuvieron ligadas a Bolivia y Argentina a pesar de la subsistencia de antiguos diferendos limítrofes no solucionados hasta 1925; por su parte, Néstor Tomás Auza (1994) indica que el recurso diplomático que el gobierno argentino proyectó presentar ante los países beligerantes para la mediación y finalización del conflicto buscó hacer partícipe a los países en donde sus legaciones estaban representadas, pero los obstáculos de la Cancillería brasilera hicieron fracasar la estrategia diplomática argentina; Andrés Cisneros y Carlos Escudé (1998) señalan que los pacifistas -casos de Mitre y de Avellaneda en el lado argentino- enarbolaron el pragmatismo económico -era más importante el comercio con Europa y el crecimiento económico que perder energías en la guerra con Chile-. La conquista del Desierto "determinó el dominio del Estado argentino sobre una enorme superficie territorial, lo cual además de ser funcional al modelo económico adoptado por el país en ese momento -incorporación de la Patagonia como zona productora de ovinos en función de la demanda británica-, fortaleció la capacidad negociadora de Argentina, permitiéndole obtener sus objetivos en el Tratado de julio de 1881". Por ello la neutralidad de Argentina se explica porque "la opción bélica entorpecía el lucrativo comercio con Europa que era, a fin de cuentas, un medio más poderoso que las propias armas"; para Carlos
Bulcourf (2003) Argentina, con el presidente Roca, “...sacrifica el Pacífico en vista a mantener la paz, organizar y lanzar el país. Se prefiere consolidar lo propio, antes que lanzarse a la conquista de lo ajeno". Y para María Luciana Cochetti (2006), la república argentina tuvo una neutralidad armada activa, ya que buscó que los países americanos tomaran partido como mediadores para terminar con la guerra. Pero su neutralidad no fue violada a pesar de darse un tráfico de armas y animales por particulares hacia Perú y Bolivia, a la que en cuanto pudo interrumpió. Sin embargo, hay un aspecto que no ha sido estudiado, este es el plano social y, más aún, el subalterno respecto a la guerra del Pacífico. Así, el presente trabajo busca rescatar y destacar la voz de los diversos grupos subalternos de emigrados en América del Sur, haciendo hincapié en sus manifestaciones públicas y cómo estas podían ser vehículo para manifestar los ideales y esfuerzos de integración como el progreso, la educación y la civilización.

Para ello nos centraremos en un caso particular, un meeting de indignación pública que se llevó a cabo el 20 de febrero de 1881 en la ciudad de Buenos Aires y que fue motivada por la difusión periodística acerca de la matanza de extranjeros en las batallas de San Juan y Miraflores en enero de 1881, cuando el ejército chileno ocupó Lima. Para hacer un acercamiento al suceso, hemos hecho uso de la fuente hemerográfica, la que en diversos diarios que circularon en Buenos Aires entre los meses de enero y marzo de 1881 nos brinda información respecto de los hechos, estos son: La República, El Nacional, La Nación, El Comercio del Plata, La Tribuna Nacional, El Siglo, La Prensa, La Pampa y La Protesta.

\section{Buenos Aires y la guerra del Pacífico}

En 1880 la ciudad de Buenos Aires se encontraba en una situación convulsa, donde se presentó la última guerra civil del siglo XIX, la que dejó un saldo de 3.000 muertos. Bajo la dirección del gobernador Carlos Tejedor, la ciudad luego de un largo proceso político terminó por enfrentarse militarmente contra el gobierno nacional del entonces presidente saliente Nicolás Avellaneda y su sucesor el general Julio Argentino Roca.

Esta coyuntura llevó a que durante casi todo el año las noticias se enfrascaron en el acontecer local dejando de lado lo que ocurría en otros países, 
pero una vez derrotadas las fuerzas revolucionarias, sancionada la ley de federalización de Buenos Aires por el Congreso e instalado el presidente Roca en el gobierno, la prensa bonaerense comenzó a informar con regularidad concerniente a los hechos del Pacífico, así los editoriales de los diversos diarios comenzaron a tomar partido de la posición que debía tomar el gobierno, La Nación y El Nacional defendiendo la neutralidad como salida política en beneficio de los derechos internacionales y los opuestos a la neutralidad, como La Tribuna Nacional, La Protesta y La República, quienes veían en el accionar chileno una política expansionista que afectaría los intereses de Argentina y a la que el gobierno debía hacer frente. Los debates en los editoriales, ya desde fines de 1880, discutían la inevitable toma de la capital peruana por parte del ejército chileno y toda la primera quincena de enero de 1881 , la incertidumbre por las noticias que brindaran mayores precisiones del desembarco y avance del ejército chileno en las costas limeñas, eran escasas, hasta que las notas periodísticas dejaron de aparecer el 15 de enero, cuando las principales batallas para la toma de Lima ya se habían consumado.

Ahora bien, hay que señalar cuál era la ruta que cruzaba la noticia para llegar a las redacciones de los diarios bonaerenses: esta partía de los corresponsales de guerra chilenos que eran enviados por diarios como El Mercurio o El Ferrocarril, enviando notas por telégrafo o mediante la red naviera que se había asegurado en casi todo el litoral del Pacífico rumbo a Valparaíso, desde ahí, bajo la redacción de periodistas chilenos, viajaba rumbo a Montevideo para por fin llegar a las redacciones porteñas;(2) lo que nos puede dar una idea del tiempo que esta tomaba en recorrer toda la ruta telegráfica, redacciones, reuniones y definiciones de contenido; así, las noticias que llegaban a Buenos Aires provenían de las redacciones chilenas, enaltecidas con el coraje propio de la guerra; un lenguaje que buscaba plantear un discurso de hegemonía y dominación, esto enaltecía la valentía, virilidad y misión civilizatoria del soldado chileno ante la cobardía, femineidad y barbarie del indio peruano y boliviano; discurso estudiado por Carmen McEvoy (2011), quien discute la implementación de estos principios civilizatorios para lograr la extensión del "Estado guerrero, comandado inicialmente por Pinto y luego por Santa María, logró culminar en la ocupación del Perú, esa larga búsqueda de la tan ansiada independencia, tanto a nivel de autonomía económica, de monopolio de la violencia y de gestión política" (McEvoy 2011: 36). El enfoque utilizado por McEvoy permite comprender, desde la óptica del observador, los aspectos más específicos de dicho constructo discursivo, ya que nos brinda detalles con fuentes de primera respecto de cómo se fue forjando dicho carácter en las iglesias, en las plazas e incluso en el mismo hogar del soldado chileno; sin embargo, creemos que el enfoque utilizado conlleva un problema que no deja de superar y es el de continuar con el binomio, o si se quiere, trinomio de los sujetos directamente involucrados, en ese sentido, el uso de fuentes externas a ello pueden brindarnos mayores respuestas la situación que acontecía entonces; así, es preciso señalar que mientras se desarrollaba la instalación en Lima del modelo político que en el futuro vendría a ser el modelo estatal chileno (McEvoy 2006), en territorio ajeno al conflicto bélico se fue dando un cuestionamiento a la idea del guerrero civilizador; en ese sentido, un caso particular como el que estamos analizando nos muestra que este se convierte en un aspecto más entre otros del discurso estatal, ya que como veremos más adelante este discurso tuvo permanencia mientras que el civilizador, ante un suceso motivado por principios disímiles, se modificó.

\section{Extranjeros en América}

La presencia de extranjeros en la defensa de Lima fue el motivo conductor para encontrarle sentido a las noticias formadas en las redacciones de los diarios bonaerenses; la aparición del extranjero europeo como sujeto político inmerso en un conflicto entre países fronterizos sudamericanos motivó la aparición de un lector ávido por conseguir todas las noticias relacionadas que aclaren lo que venía ocurriendo en tierras lejanas.

El Nacional, haciendo alarde de su capacidad informativa ante la falta de noticias de lo que ocurría en Lima, informa de las batallas liberadas en Lima, señalando: "Un batallón compuesto de italianos peleó en la sangrienta batalla de Chorrillos, el que fue completamente exterminado" 3 . Hay que resaltar este detalle porque notamos que la atención de los sucesos en el Pacífico si bien es cierto buscaban dar mayores detalles de la contienda bélica, no dejaban de señalar la participación de españoles, franceses y más aún de italianos en la defensa de Lima; $L a$ Nación informa: "Chorrillos, Barranco y Miraflores 
destruidos completamente. En Chorrillos peleó un cuerpo de garibaldinos compuesto de italianos, fue exterminado. Confirman que los peruanos rompieron el fuego traidoramente durante la tregua. Asegúrase que el ejército peruano empleó balas explosivas"4. Como veremos la seguidilla de reportes buscan informar de los sucesos pero cada vez más ensalzando y haciendo reparos con la participación de extranjeros en las batallas.

El jueves 10 de febrero de 1881 La Nación publica un telegrama recibido desde Montevideo que afirma la muerte de italianos garibaldinos, pero además señala que habrían "españoles". El lunes 14 de febrero de 1881 El Nacional informa la "hecatombe de los cuerpos de voluntarios italianos, franceses y españoles".

El viernes 11 en La Tribuna Nacional se menciona que son los diarios chilenos los que narran los acontecimientos de salvajismo, dando detalles espantosos y haciendo alarde de franqueza hacia ellos. De los italianos dirá:

"Es un hecho indudable que los italianos domiciliados en Lima formaron un batallón de 600 plazas y el cual bautizaron con el nombre de Garibaldi. Este cuerpo peleó en Miraflores por supuesto atrincherados como sus amigos los peruanos, y fue a los navales a quienes les tocó dar buena cuenta de él" (p. 1).

La redacción de La República es bastante ilustrativa acerca de la opinión que se venía formando de la actitud de los diarios chilenos al informar lo sucedido en Lima, dice:

"La prensa chilena nos hace saber también que un batallón de italianos y otro de españoles fueron pasados a degüello y exterminados por los chilenos, por el solo delito de haber cooperado a la defensa de la independencia del Perú peleando u muriendo al lado de los peruanos".

¿Qué saña ha desplegado el ejército chileno contra los extranjeros!

Lynch hizo saltar con dinamita los valiosos establecimientos industriales de los neutrales, como lo confesó el señor Vicuña Mackenna en el Senado chileno -y no contento con esa venganza, fueron pasados a degüello los extranjeros en Chorrillos y Miraflores.

Mírense en ese espejo los italianos y los españoles, principalmente estos últimos deben recordar que en 1862 fueron expulsados en masa de Chile en un término perentorio.

Chile no gusta de los extranjeros, los persige siempre, los espulsó, les incendia sus propiedades o los pasa a cuchillo, y a pesar de eso aspira a ser en el Pacífico el gobierno más culto, más humanitario y más civilizado"5.

La prensa porteña informa el 14 de febrero de la aparición en Montevideo de un artículo anónimo, que a todas luces proviene de un autor chileno, este causó gran indignación en dicha ciudad, $E l$ Nacional señala que el artículo se refiere a los hechos en términos de "hecatombe de los cuerpos de voluntarios italianos, franceses y españoles...", y que llamaría "traidores temibles" a los italianos, además de mencionar que la situación de los italianos en Chile es poco menos que la de ilotas. Para los redactores de El Nacional, la relevancia del ímpetu del anónimo estaría en tratarse no solo de la opinión de un individuo, sino de ser la opinión de Chile entero:

“...desde un hombre más conspicuo, como el Sr. Ibáñez que hace poco sostenía en el Senado chileno que todo prisionero rendido debía pasarse a degüello, por el delito de haber combatido contra su patria, hasta el último roto, que reciba de manos de las autoridades de su país, como una sanción anticipada de sus actos, el corvo con que ha de ultimar al caído"6.

Preocupación que se generalizó en la prensa porteña, El Nacional dice:

"Para encontrar las causas de este odio brutal que palpita en Chile contra el extranjero, es necesario recordar la organización social de aquel país, viviendo, bajo ese punto de vista, en pleno espíritu colonial. Chile está a cien años atrás de nosotros; allí, si se penetra a las bajas capas del pueblo, a donde no ha descendido la educación que ilumina, hay 
en su forma más rudimentaria, no será difícil hablar con gente que crea, como los mestizos del siglo XVI que los herejes extranjeros huelen todos a azufre y tienen cola" $"$.

En los diversos diarios podemos ver la opinión formada de la actitud de Chile, privada de los principios intelectuales que los columnistas bonaerenses consideraban como propios de los logros de la ciencia, la razón y los principios universales de la modernización y la civilización. Dice El Nacional:

"Son los jóvenes oficiales del Naval de Valparaíso, salidos de las Universidades, lleno el espíritu de las nobles ideas de humanidad que la ilustración desenvuelve, que azuzan al soldado ebrio de sangre y tal vez manchan su propia espada enterrándolos en el corazón del moribundo"8.

El Siglo de Montevideo señala que el ejército chileno organizó un regimiento de "chinos asiáticos" que marchaban a la retaguardia armados de corvos: "Cuando caían peruanos heridos o muertos en las batallas corrían los chinos y los degollaban, durante 40 minutos de operación"9. Ahora bien, los chinos culíes que acompañaban al ejército chileno fueron aquellos que en medio del desorden de la guerra fueron liberándose del trabajo forzado al cual estaban obligados de cumplir por un contrato que les permitió llegar a América, en las diversas haciendas del Sur de Lima. Es importante resaltar que la figura de Patricio Lynch, al haber estado hacía años comisionado a China, conocía bien las costumbres y el idioma de esta población, por lo que su presencia resultó efectiva para poder ganarse el apoyo de quienes conociendo el terreno guiaron muchas veces al ejército de ocupación ${ }^{10}$.

A partir de la quincena de febrero, los diarios informan de la presencia de asociaciones de extranjeros que, en solidaridad a los caídos en Lima, han comenzado a movilizarse y buscan hacer oír su voz de queja; el primero fue la Sociedad Masónica del Gran Oriente Uruguayo, quienes resolvieron vestir de luto sus talleres por tres meses como protesta contra los actos de la guerra del Pacífico. Esta noticia tuvo su repercusión en las asociaciones de extranjeros porteña, ya que a partir del 16 de febrero miembros representativos de la colonia de extranjeros en Buenos Aires inician ciertas reuniones que tendrán por finalidad llevar a cabo una manifestación pública que integre la indignación de italianos, españoles y franceses por las noticias de la matanza de extranjeros en Lima:
"Hemos notado hoy en los círculos más importantes y prestigiosos de italianos, es- pañoles y franceses, también un remarcable entusiasmo por la idea de llevar a debido efecto este meeting en el cual se protestará de la manera más ardiente contra la actitud por el ejército chileno con los extranjeros degollados bárbaramente en Chorrillos" ${ }^{11}$.

En las reuniones hicieron su aparición delegados de las siguientes sociedades: Reducci delle Patrie Bataglie, Club Espalo, Club Catalá, Centro Gallego, La Morina y la Urat-Bac; conociéndose que la colonia francesa también tomaría parte de dichas manifestaciones ${ }^{12}$.

En un primer momento los extranjeros organizadores del meeting definieron tres puntos:

- Se aceptó por unanimidad la idea de celebrar un meeting el domingo próximo para protestar solemnemente contra los hechos bárbaros ejecutados por el ejército chileno.

- Para organizar el meeting y lo demás relativo a esa demostración se nombró una comisión compuesta de los señores Gallarani, Blosi, Cittadini, Cimone, Fineroni, Canalli, Alen, Firrast, Alfonso, Solá, López Gomara, Apellanis, Ebelot, Walis, Daireaux y Daumas y además los presidentes de todas las sociedades italianas, francesas y españolas de Buenos Aires.

- Esta comisión se reunirá nuevamente... en el mismo local, a fin de confeccionar el programa del meeting y designar el sitio y hora en que tendrá lugar. Además solicitaron a todos los que asistan al meeting que concurran vestidos de luto.

El diario La Protesta informó que la reunión de extranjeros nombró presidente de la Comisión para realizar el meeting al señor Carlos Gallarini en una sesión que habría durado hasta las once de la noche y a ella asistieron representantes de la prensa: La Patria Argentina, La Tribuna Argentina, La Nación, La Bandera Liberal y La Protesta; esto evidencia el interés de la prensa por seguir paso a paso la organización de los extranjeros ${ }^{13}$.

La reunión del 18 de febrero estableció el programa: 
- Que el doctor Gallarani; solicitase al Presidente de la República permiso para la asamblea proyectada.

- Que una vez conseguido esto, quedaba designada para efectuarla el domingo próximo.

- Que los señores Cittadini, Blosi y Aleu confeccionasen la propuesta acordada.

- Que en el acto del meeting, tomasen la palabra como oradores - por los residentes españoles, los señores Ased y Barros, por los italianos, Cittadini y Pezzi-, por los franceses, Daumas y Daireaux.

Todas estas coordinaciones no pasaron inadvertidas para los diarios, estos las enaltecieron como muestra de la eficiencia de las colonias. Su contraparte radicó en las reacciones que motivó la noticia que habría llegado a Chile por la movilización de extranjeros que buscaba pronunciarse contra las acciones del ejército chileno. La Prensa informa que el ministro de Italia en Chile, el conde Fabio Sanminiatelli, dirigió un despacho al ministro italiano Ippolito Garrou residente en Montevideo, en este asegura que estaría "desmentida la noticia de que hubiese un cuerpo de italianos en las últimas batallas"14. Ahora bien, este no es un hecho singular, por el contrario, La Pampa señala que: "Ha habido en esta una mistificación singular, que hacía creer que el meeting no se celebraría: pero se ha decidió llevarlo a cabo. Nos referimos al telegrama que se atribuye al ministro italiano en Chile, en que se niega que hubiese habido en el ejército del Perú tales legiones" 15 . Formándose así una corriente de opinión contra el ministro italiano en Chile; El Siglo de Montevideo llamaba encubridor a Sanminiatelli al haber procedido de modo "incalificable" por ocultar tales horrores ${ }^{16}$.

Durante la semana que siguió al meeting, los diarios bonaerenses escribieron concerniente a su impacto destacando el empeño de los extranjeros por manifestar su pesar y solidaridad por sus compatriotas caídos en la ocupación de Lima. Diversos diarios hicieron suya la proclama de los extranjeros, el diario La Protesta dice en su editorial:

"No lamentamos solamente la guerra de los extranjeros degollados después de la batalla, de los heridos europeos ultimados por los chinos, pegados como hienas a la retaguardia del ejército invasor, para agregar a los horrores de la batalla las abominaciones del saqueo y del degüello sistemático. Lamentamos también la muerte de los peruanos que han perecido bajo la crueldad de los salvajes de raza amarilla, desencadenados por salvajes más bárbaros, los vándalos de guante de Santiago. Lamentamos sobre todo la mancha inferida al nombre americano, a la civilización, a las ideas de dignidad humana, que son la última expresión del progreso"17.

En busca de enaltecer más los ánimos $L a$ República hace público el juramento que habrían hecho los chinos al ejército chileno:

"La ceremonia del juramento que a la bandera chilena prestaron los chinos, fue un celebrado acontecimiento en el campamento conquistador por su originalidad. Uno de los chinos que hacía de jefe, convocó a todos ellos y después de arengarlos, compeliéndose a servir a Chile, haciéndola su segunda patria los condujo ante el general Baquedano, delante el cual el mismo sujeto manifestó la firme decisión de él y los suyos para combatir a la sombra del pabellón de Chile, abjurando de su propia patria que los había abandonado. En seguida degollaron un gallo, recogiendo la sangre en una fuente, y acercándose a ella untaron sus lenguas con dicha sangre, siendo esta costumbre china el modo más solemne de jurar. A renglón seguido se alistaron formando una verdadera hueste armada de garrotes y caballeros en sendas mulas" 18 .

Pero la protesta no quedó solo en Buenos Aires, en la cercana Montevideo también se presentaron otras manifestaciones e incluso los comercios de extranjeros fueron cerrados en señal de luto ante la muerte de sus compatriotas en Lima.

El meeting celebrado en oposición a Chile nos ayuda a entender el protagonismo que los emigrados buscan tener en la sociedad que los recibe, su organización y los principios de civilización, educación y modernidad que expresan, son parte de los mismos principios del país en el que ahora viven y se desarrollan; la integración a la Argentina sería entonces el marco en el que deciden manifestarse, criticando y mostrando su indignación ante aquellos que van contra dichos ideales. 
Asimismo, la atención que la prensa bonaerense da a los hechos ocurridos en Lima son un reflejo de los intereses del lector interesado en descubrir lo ocurrido con sus compatriotas extranjeros, sin embargo se presenta en estos medios un nuevo frente de batalla que no se dio con las armas, la prensa argentina juega así un rol de presión a los medios periodísticos chilenos que ante las circunstancias del meeting y otras acciones en Buenos Aires y Montevideo, dieron un giro al discurso de ímpetu patriotero con que habían tratado el tema de la ocupación de Lima.

\section{La indignación de los extranjeros}

Los sucesos son rápidos, comenzaron a las tres de la tarde cuando la Comisión Directiva que se encontraba reunida en el conocido Teatro Colón, acompañada de una banda musical de la Sociedad Stella de Ytalia marchó camino a la Plaza de Retiro al norte de la ciudad vía la calle Rivadavia, la que como es típico en estas actividades fueron sumándoseles personas y asociaciones; la cantidad de la asistencia no es clara, diversos diarios informan de manera desigual; según el diario La Protesta habrían unas veinte mil almas, para El Siglo habrían ocho mil. La ruta estaba diseñada para hacer altos en ciertos edificios como el Club Unión Argentina o la Legación Peruana, donde el ministro Gómez Sánchez los recibió desde los balcones junto a personal de la Legación; luego la muchedumbre pasó a la estatua del general San Martín donde los esperaba un grupo de gente en medio de la algarabía y el ánimo de fiesta; se había instalado un tablado desde donde hablarían los oradores, todos llevaban una escarapela blanca en el pecho, dejándose ver cómo flameaban las banderas argentina, peruana, italiana, española y francesa. El promotor de la actividad, el distinguido italiano Dr. Gallarani, tomó la palabra, esta resulta de suma importancia transcribirla:

Honor a los mártires italianos, españoles y franceses, asesinados en las batallas de Chorrillos y Miraflores. Vergüenza eterna para el ejército que ha manchado sus banderas con la sangre derramada contra el derecho de gentes y los inviolables principios de la civilización moderna. Una lástima también y un deseo de resurrección para el noble vendido ${ }^{19}$.

La programación se cumplió en cada punto, las palabras del español Dr. Antonio de P. Aleu fueron de exaltación, ya que sería la proclama que habría elaborado la Comisión y que transcribimos completa:

\section{Italianos, españoles, franceses}

El Ejército chileno, sediento de sangre y necesitando encargarse en ella pata convencerse de su triunfo, ha inmolado de modo tan repugnante como torpe, á su ira y sus rencores, los restos de las legiones formadas por nuestros compatriotas y que con tanta abnegación y heroísmo ofrecieron su brazo, el valor de su alma y la muralla de su pecho, al país que les sirviera de segunda patria. Los italianos, franceses y españoles muertos en el Perú, han escrito con su sangre una nueva página de gloria en la historia de la raza latina y añadido un timbre más á nuestros pendones, esos pendones que durante siglos han marchado á la cabeza de la civilización y que elevándose gigantes y atrevidos hasta el suelo han profundizado los misterios de la historia de la humanidad, uniéndola con el principio de su origen. Nuestros hermanos han caído en su puesto, y los que no murieron durante la batalla, fueron después asesinados por el traidor corvo chileno. Pero no terminaba ahí el espectáculo, que era llevado al colmo de la crueldad y la barbarie. Un cuerpo formado por individuos de distinta raza, llevaba en pos el triunfador ejército, para que separase del tronco las cabezas de nuestros hermanos. ¡Hermanos, compatriotas! En nombre del patriotismo, de la civilización, de todos los sentimientos honrados, de esas madres que lloran en nuestras patrias que se cubren de luto, es preciso protestar contra el crimen de que ha sido víctima nuestra raza. Italianos, franceses, españoles: lo que hay hecho el ejército chileno con nuestros hermanos del Perú, es tal vez la suerte que nos espera porque á pesar de su bárbara amenaza no hemos de renegar de nuestra dignidad é hidalguía y gustosos armaremos nuestro brazo para defender nuestro hogar, nuestra familia y el país que nos hospede, si la planta chilena osara hollar el libre suelo argentino. ¡Todos somos hermanos! Maldición, sobre el que nos ha arrebatado tan preciosas vidas!

Finalizados los discursos a las cinco de la tarde la muchedumbre se disolvió con la mayor tranquilidad, según indican los periódicos, los que a su vez evidenciaron una excelente percepción hacia los extranjeros, indicando que se trataba de una colectividad que aportaba al desarrollo del 
país, destacando siempre el orden, las ideas y la organización.

\section{Las repercusiones}

En los días siguientes al meeting, los periódicos comentaron del impacto que tuvo esta manifestación popular, motivando otras similares en distintas provincias, el apoyo al meeting bonaerense quedó graficado en La Protesta:

En Chascomús. Anoche celebrose una numerosa reunión de ciudadanos españoles, italianos, franceses para ponerse de acuerdo sobre la reunión de hoy que tendrán por objeto protestar de la masacre de españoles, italianos en las batallas de Chorrillos y Miraflores. Se ve pues que el sentimiento de reprobación es unánime en todas partes. Reinó la mayor armonía de ideas resolviéndose que la manifestación sea colectiva. La actitud de las colonias referidas no puede ser más digna...

Otras manifestaciones se presentaron en Uruguay, como la que organizó el Centro Gallego de Montevideo ${ }^{20}$.

El jueves 24 de febrero el diario El Comercio del Plata informa de llegada de una persona a la Argentina que habría dado testimonio de lo ocurrido en los degüellos a los extranjeros:

\begin{abstract}
"Efectivamente, no han habido legiones extranjeras, pero, es un cuerpo de ciudadanos de las tres nacionalidades formado en Asociaciones tituladas 'Bomba Garibaldi' para ir sofocando los incendios que ocurrieran. Trabado el combate estos se hicieron un lado y se pusieron el uniforme de Bomberos que como se comprende era neutral, pues ni siquiera estaban armados" 21 .
\end{abstract}

El diario resalta que este hecho incrementa la gravedad del caso, ya que se ha cometido doble crimen al estar estos extranjeros desarmados. $\mathrm{La}$ Legación de Italia en Lima confirma el desmentido, como aparece en La Protesta: “... los italianos no tomaron parte allí en las últimas batallas, por consiguiente no hay tal masacre ni mucho menos motivos de alarma para la colonia extranjera"22.
Pero El Nacional cuestiona estos desmentidos, ya que los diarios chilenos -hasta el 10 de febrero- confirmaban los degüellos de extranjeros en Chorrillos cuando aún no se había dado el meeting en protesta; esto es, que el meeting habría ejercido algún tipo de presión en la política chilena y lo ha llevado a cambiar de proceder: "Y así es en efecto, por más que La Libertad y otro diario pretendan tapar el cielo con un arnero. Los diarios alcanzan hasta el 10 del actual, época en que no se conocían aún a fondo en Chile la protesta que los pueblos civilizados levantaban contra tamaña barbarie"23.

El debate quedó abierto entre quienes daban fe de la matanza de extranjeros en Lima y quienes lo desmentían, pero lo concreto es que el meeting se realizó y logró dar a conocer la reprobación a los actos de "barbarie" del ejército chileno, lo que evidenciaría su importancia e incluso sus logros, como el hecho de conseguir un cambio de actitud en la prensa chilena o el haber captado la atención del cuerpo diplomático italiano en Perú y en Chile para tratar de interceder y calmar los ánimos de sus colonias, en cierta medida podríamos decir incluso que el meeting habría ejercido cierta presión en la misma dirección de la estrategia mediática de la guerra del Pacífico.

\section{Conclusiones}

El manejo de la información de la prensa argentina, antes de los sucesos de enero de 1881, estuvo relativamente opacado por la política interna argentina debido a los intentos de federalización del país. La inminente ocupación de la capital limeña se convirtió en un tema constante en los editoriales de casi todos los diarios, ya que la idea de que un país americano invada a otro era considerada como un retroceso en el avance de la civilización, con ello, el americanismo se evidenciaba como un ideal aún no consolidado.

El papel que juega un país neutral debe examinarse no solo en sus relaciones internacionales por medio de su política, sino también al nivel de los agentes subalternos, quienes son independientes del gobierno y pueden formular sus propias ideas acordes o en oposición a la conducta de sus dirigentes políticos; por ello, por medios como la prensa podemos estudiar cómo dichos grupos responden ante una situación externa que termina por afectarlos en distintos grados.

Ante las noticias de la matanza de extranjeros en la defensa de la capital peruana los grupos 
subalternos de emigrados en Buenos Aires pusieron a prueba su capacidad de organización en pocos días y lograron la definición de acuerdos entre diversas colonias a pesar de las diferencias que podían tener entre ellas, con esto pudieron elaborar una proclama pública contra Chile.

Los grupos subalternos de emigrados en Buenos Aires buscaron por un lado llamar la atención de las autoridades argentinas hacia los sucesos en Lima y por otro lado definir sus mecanismos de inserción a la sociedad que los estaba recibiendo; es importante destacar que el discurso utilizado por italianos, españoles y franceses en este acto público es el de la educación, el orden y la civilización; con ello se pone en claro que al igual que Argentina como país, ellos también defienden esos principios; no es entonces solo una manifestación de rechazo sino una muestra de la necesidad de inserción y de mayor representación política la que los emigrados buscaron conseguir cuando alzaron su voz.

\section{Referencias Citadas}

Auza, N.T.

1994 La mediación argentina en la guerra del Pacífico. 18801882. Res Gesta, 33: 43-81. Buenos Aires

Bulcourf, C.G.

2003 Diplomacia argentina en la Guerra del Pacífico. Ediciones cooperativas, Buenos Aires.

Cochetti, M.L.

2006 La neutralidad activa argentina en la guerra del Pacífico. La promoción del tráfico de armas hacia los ejércitos de Bolivia y Perú. FLACSO.

Chou, Diego L.

2001 Los chinos en la Guerra del Pacífico, Revista de Historia de América, 129: 197-224.

Desbordes, R.

2004 Migrations et réseaux d'information au XIXème siècle: Les agences Havas-Reuter en Amérique du Sud, 1874-1876. Amérique Latine Histoire et Mémoire. Les Cahiers ALHIM [En línea], 8 I 2004, Publicado el 14 febrero 2005, consultado el 12 marzo 2015. URL: http://alhim.revues.org/412

Guice, C Norman

1982 Giving Peru a choice: Federico Larrañaga and el Canal de Panamã, Academy of American Franciscan History, 39: 85-106.
McEvoy, C.

2006 Chile en Perú: guerra y construcción estatal en Sudamérica, 1881-1884, Revista de Indias 236: 195-216.

McEvoy, C.

2011 Guerreros civilizadores. Política, sociedad y cultura en Chile durante la Guerra del Pacífico. Universidad Diego Portales, Santiago.

Rodríguez Pastor, $\mathrm{H}$.

2007 Los chinos en la Guerra del Pacífico, en José Chaupis y Emilio Rosario (Comps.), La Guerra del Pacífico. Aportes para repensar su historia, pp. 251-280. UNMSM-Editorial Línea Andina, Lima.

Vidaurreta, A.

1988 Conflictos entre política y grupos de presión. Argentina y los aliados del Pacífico, 1872-1883, Revista de Historia de América, 105: 7-44.

Yrigoyen, $\mathrm{P}$.

1919 La adhesión de la república argentina al tratado de Alianza defensiva Perú-boliviano de 1873. Sanmartín y Cía., Lima.

Yrigoyen, $\mathrm{P}$.

1921 La alianza Perú-Boliviano-Argentina y la declaratoria de guerra de Chile. Sanmartín y Cía., Lima.

\section{Notas}

1 Los artículos de Ricardo Palma en el canal de Panamá han sido publicados por Mosca Azul editores en 1984 bajo el título de Crónicas de la Guerra con Chile (1881-1882).

2 El telégrafo, medio de comunicación por excelencia en la segunda mitad del siglo XIX, llegó al Perú por medio de un Decreto en 1857 que condecía a Augusto Goné la exclusividad para la construcción de las líneas de Lima al Callao y de Lima a cerro de Pasco, sin embargo el contrato fue cancelado por incumplimiento y recién en 1860 se trasmitieron 8,906 telegramas comerciales como oficiales, en 1867 se funda la Compañía Nacional de Telegrafía bajo la dirección de Carlos Paz Soldán como ente privado, pero con la política de estatización del presidente Pardo el 27 de abril de 1875 quedaba la Compañía bajo dominio del Estado, pero ante la imposibilidad de cubrir los gastos, regresa a manos de Paz Soldán por concesión de 8 años. Para 1878 el telégrafo es declarado servicio nacional, contando con $2.525 \mathrm{~km}$ de cableado bajo el sistema Morse con 53 oficinas y 65 aparatos; sin embargo, en 1879 y como parte del dominio marítimo, el ejército chileno intervino el telégrafo cortando la comunicación del Sur con Lima. También hay que señalar la apertura de agencias de información europeas como la francesa Havas-Reuter. Para mayores detalles ver: Rhoda Desbordes (2005).

El Nacional, martes 25 de enero de 1881.

La Nación, miércoles 26 de enero de 1881.

La República, viernes 11 de febrero de 1881.

El Nacional, lunes 14 de febrero de 1881.

El Nacional, lunes 14 de febrero de 1881.

El Nacional, lunes 14 de febrero de 1881.

El Nacional, miércoles 16 de febrero de 1881.

10 Existe una amplia bibliografía que nos puede dar luces hacia el sistema de sometimiento al que estaban obligados los chinos culíes, reflejando aspectos económicos y sociales tanto en el Perú como en Chile, para mayores detalles ver: Diego L. CHOU, "Los chinos en la Guerra del Pacífico", Revista de Historia de América, México, 
2001, No 129, pp. 197-224; Humberto Rodríguez Pastor, "Los chinos en la Guerra del Pacífico", en José Chaupis y Emilio Rosario (Comp.), La Guerra del Pacífico. Aportes para repensar su historia, Lima: UNMSM-Editorial Línea Andina, 2007, pp. 251-280. El Nacional, jueves 17 de febrero de 1881.

La Protesta y El Nacional del jueves 17 de febrero de 1881. La Protesta, viernes 18 de febrero de 1881 . La Prensa, sábado 19 de febrero.
La Pampa, domingo 20 de febrero de 1881.

El Nacional, jueves 24 de febrero de 1881.

La Protesta, martes 22 de febrero de 1881.

La República, domingo 20 de febrero de 1881.

El Comercio del Plata, lunes 21 de febrero de 1881.

El Nacional, jueves 10 de marzo de 1881 .

La Protesta, jueves 03 de marzo de 1881.

La Protesta, jueves 24 de febrero de 1881.

El Nacional, jueves 24 de febrero de 1881. 